\title{
Contextualizing Instruction: Leveraging Students' Prior Knowledge and Experiences to Foster Understanding of Middle School Science
}

\author{
Ann E. Rivet, ${ }^{1}$ Joseph S. Krajcik ${ }^{2}$ \\ ${ }^{1}$ Teachers College, Columbia University, Box 210, 525 West 120th Street, \\ New York, New York 10027 \\ ${ }^{2}$ School of Education, University of Michigan, Ann Arbor, Michigan
}

Received 8 July 2005; Accepted 14 January 2007

Abstract: Contextualizing science instruction involves utilizing students' prior knowledge and everyday experiences as a catalyst for understanding challenging science concepts. This study of two middle school science classrooms examined how students utilized the contextualizing aspects of projectbased instruction and its relationship to their science learning. Observations of focus students' participation during instruction were described in terms of a contextualizing score for their use of the project features to support their learning. Pre/posttests were administered and students' final artifacts were collected and evaluated. The results of these assessments were compared with students' contextualizing scores, demonstrating a strong positive correlation between them. These findings provide evidence to support claims of contextualizing instruction as a means to facilitate student learning, and point toward future consideration of this instructional method in broader research studies and the design of science learning environments. (C) 2007 Wiley Periodicals, Inc. J Res Sci Teach 45: 79-100, 2008

Keywords: physical science; problem-based learning; curriculum development; middle school science; classroom research

Many programs and researchers call for structuring science curriculum so as to connect to students' lives. Calls for using "authentic tasks" (i.e., Lee \& Songer, 2003), making science "relevant" (i.e., Fusco, 2001), promoting community connections, and building from local contexts (i.e., Bouillion \& Gomez, 2001) are common features in today's science education reform initiatives. Such efforts to contextualize instruction attempt to leverage from students' prior knowledge and experiences to foster understanding of challenging science concepts. However, although much literature has touted the benefits of such efforts to contextualize science instruction to improve learning, few studies have explored this relationship and little research exists to substantiate such claims.

\footnotetext{
Contract grant sponsor: National Science Foundation (Center for Learning Technologies in Urban Schools); Contract grant number: 0830310 A605.

Correspondence to: Ann E. Rivet; E-mail: rivet@tc.columbia.edu

DOI 10.1002/tea.20203

Published online 5 November 2007 in Wiley InterScience (www.interscience.wiley.com).
} 
One instructional model that incorporates efforts to contextualize instruction is project-based science (Krajcik, Czerniak, \& Berger, 2002; Marx, Blumenfeld, Krajcik, \& Soloway, 1997). Building from a foundation in theories of situated learning (Brown, Collins, \& Duguid, 1989; Lave \& Wenger, 1991), project-based science attempts to support students' developing understandings by bringing their prior knowledge and experiences to the forefront in the learning situation (Cognition and Technology Group at Vanderbilt [CTGV], 1992b) and fostering integration and interconnections between ideas (Blumenfeld, Marx, Patrick, Krajcik, \& Soloway, 1997). This study explores students' use of the contextualizing aspects of project-based science during classroom instruction and its relationship to students' science learning. Focus students from two urban middle school classrooms were observed as they participated in an eighth-grade project-based science unit and were characterized in terms of their use of the contextualizing features of the project as a means to support their developing understanding. The results were used to explore the relationship between contextualizing instruction and student learning in these science classrooms.

\section{Review of the Literature}

\section{Defining Contextualizing Instruction}

In this study contextualizing instruction refers to the utilization of particular situations or events that occur outside of science class or are of particular interest to students to motivate and guide the presentation of science ideas and concepts. Contextualizing often takes the form of realworld examples or problems that are meaningful to students personally, to the local area, or to the scientific community. These are situations in which students may have some experience with (either directly or indirectly) prior to or in conjunction with the presentation of target ideas in science class, and that students engage with over extended periods of time.

Contextualizing instruction takes on a particularly important role within the framework of project-based science. Project-based science is similar to problem-based learning and other social-constructivist, inquiry-based design models in that students develop rich understandings of science concepts within the context of a contextualized real-world situation guided by a driving question (Krajcik et al., 2002). Problem-based learning focuses on the development of models as tools (Kolodner, Crismond, Gray, Holbrook, \& Puntambekar, 1998) and the process of developing a solution as well as the resulting product are designed to play important roles in promoting learning (Hmelo, Holton, \& Kolodner, 2000). Project-based science differs, however, in that a greater emphasis is placed on addressing the problem situation holistically from multiple perspectives (Marx et al., 1997), rather than solving a problem or designing a solution. Thus, the intended role of the problem situation and contextualizing features is different in this model as compared to other inquiry-based instructional designs.

Within the project-based science model, there are four characteristics of contextualizing instruction. The first is the use of problems and situations as the focus of instruction that are meaningful to students, in that they have implications to students outside of school (Edelson, Gordin, \& Pea, 1999). Research has found that students sustain their attention more continuously and process information at deeper levels when they have a personal interest or investment in the domain (Brophy, 1998). However, it is not sufficient for the problems only to be of interest. They must also encompass worthwhile science content and leverage students' interest or experience for them to engage with the content. The second characteristic is that the meaningful problem provides a need-to-know situation to learn specific scientific ideas and concepts. The problem situation motivates a reason to understand the content and engage in the task of science learning, and provides 
a purpose for knowing science ideas and concepts (Krajcik et al., 2002). The third characteristic is the use of some form of anchoring situation and event (CTGV, 1992b; Marx et al., 1997) to engage students with the scientific concepts that are addressed in the problem or situation, and it revisited repeatedly during instruction. Anchoring events provide students with a common experience from which they can relate new information (Sherwood, Kinzer, Bransford, \& Franks, 1987). Experimental research has shown that rich contextualizing features such as anchoring events promote memory recall and subsequent transfer of information to new settings (CTGV, 1992b). The fourth chracteristic is engagement with the meaningful problem over an extended period of time (Marx et al., 1997). Extended study allows for analysis of the problem from multiple perspectives.

The Center for Learning Technologies in Urban Schools (LeTUS) has developed science curriculum materials that incorporate new ideas about teaching and learning through project-based instruction that fosters contextualizing students' experiences (Krajcik, Blumenfeld, Marx, \& Soloway, 1994; Krajcik et al., 2002; Marx et al., 1997). Contextualization is one of the seven design principles for project-based science (Singer, Marx, Krajcik, \& Clay-Chambers, 2000). Within each LeTUS project-based science unit, there are five design features that support contextualizing instruction: (1) there is use of a driving question to introduce and structure the context of the project; (2) there is an anchoring event or experience that all students share; (3) the project activities are linked and woven in with the driving question and contextualizing theme; (4) student artifacts or projects related to the contextualizing theme are developed during the unit; and (5) there is a culminating event or experience bringing closure to the project (Rivet \& Krajcik, 2004).

Contextualizing instruction is promoted as sound educational practice by national science education reform efforts. The National Science Education Standards (National Research Council, 1996) recognize the importance of contextualizing to students' lives as an enduring theme in their proposed reforms:

Science content must be embedded in a variety of curriculum patterns that are developmentally appropriate, interesting, and relevant to students' lives. . .regardless of organization, the science program should emphasize understanding natural phenomena and science-related social issues that students encounter in everyday life. (p. 212-213)

Many educational programs have also embraced the use of this instructional method. For example, the Cognition and Technology Group at Vanderbilt developed a video-based mathematics series that engages students in solving real-world problems in the context of following the adventures of a young man named Jasper Woodbury (CTGV, 1992b). Edelson and colleagues (1999) designed visualization software and curriculum to help students explore the scientific complexities and social implications of global warming. Songer's Kids as Global Scientists program (Songer, 1993) engages students in studying their local weather and sharing data with students in other parts of the world. Linn (1998) developed the Web Integrated Science Environment (WISE), which allows students to examine real-world evidence and analyze current scientific controversies. However, few experimental studies have been conducted in the area of contextualizing instruction and little is known about how this method plays out in science classrooms to support learning. Such information about the use of contextualizing instruction as it is enacted in the classroom and its relationship to students' learning is needed to support the theorized claims regarding its benefits. Such information will also inform both designers of contextualized learning environments in science and professional development efforts that promote contextualizing instruction in science classrooms. 


\section{Proposed Benefits of Contextualizing Instruction}

Contextualizing instruction has been theorized to help students make sense of complex scientific ideas, because the use of meaningful problems or situations provides students with a cognitive framework for which to connect or "anchor" knowledge (CTGV, 1992b; Kozma, 1991). The cognitive framework acts like a structure upon which abstract ideas can be linked with prior understanding and fixed in long-term memory. In this way, the use of meaningful problems over extended periods of time makes the learning situation "bushier" (Kozma, 1991) with more available links onto which students can connect ideas. Learning occurs when new information is "hooked" and embellished by previous knowledge held in memory (McGilly, 1994).

Classroom tasks influence students by directing their attention to particular aspects of the content and specifying ways to process information (Doyle, 1983). Contextualizing instruction focuses students' attention on the interrelationships between concepts. This is in contrast to more subject-specific instruction that emphasizes the presentation and recall of information but not necessarily the connections between them. In addition, contextualizing instruction helps learners to organize and integrate knowledge by engaging students with scientific ideas from multiple perspectives while pursuing solutions to meaningful problems (Blumenfeld et al., 1997). Through engagement with concepts and ideas from different perspectives, students see how the ideas are applied in different settings and build their own representations of concepts (Marx et al., 1997). Meaningful problem situations also provide learners with a perspective for incorporating new knowledge into their exiting schema, as well as opportunities to apply their knowledge (Edelson et al., 1999).

Contextualizing instruction is believed to promote transfer of science ideas to other contexts, because students learn to relate content idea to problems and situations meaningful in their lives and the real world. Rich contextualizing features promote memory recall and thus transfer (CTGV, 1992b, 1997). In addition, contextualizing instruction engages students in active use of their developing scientific understandings. Active learning, rather than passive reception, is needed for students to gain an understanding of the application of their knowledge under different circumstances. Active learning in multiple contexts is claimed to support the abstraction of knowledge, and thus transfer (Collins, Brown, \& Holum, 1991).

However, it has also been found that novice learners do not always make connections between new information and prior knowledge or everyday experiences in ways that are productive for learning (Land, 2000). Some have argued that due to the underdeveloped knowledge structures and the lack of experience of novice learners, engaging them in effective theory-building in everyday contexts which can be considerably complex may be overly optimistic and, at times, counterproductive. Novices may misapply prior experiences or use observations to unknowingly strengthen their naive theories. Although there are many benefits in building upon meaningful problems and real-world situations, the instructional challenges associated with effectively realizing these benefits are formidable (Land, 2000).

Few studies have explored the influence of contextualizing instruction on the development of relationships between science ideas and real-world situations and problems. Most research has been framed in the context of students' ability to transfer information to new settings (CTGV, 1997). Even more rare have been classroom-based studies that consider the relationship between instruction and learning. The present study addresses these gaps in the literature by looking closely at students' use of contextualizing features during enactment of a project-based science unit and relationships to science learning.

The question guiding our study is: What is the relationship between students' use of the contextualizing features during project-based instruction and their science learning? The research 
methods and our findings are described in several parts. First, the background of the study, including the classroom setting, instructional context, and selection of focus students, is described. Then the data collection and analysis methods of classroom observations to characterize students' use of the contextualizing aspects of the project are explained. This is followed by a discussion of students' contextualizing scores. Next, the two learning assessments are described along with a discussion of students' performances on each assessment. Then the analysis of the results of these assessments with students' contextualizing score is described in detail. We conclude with a discussion of the results of this research.

Background

\section{Setting}

This study focused on two eighth-grade classrooms in urban Detroit. These classes, each with approximately 30 students, were led by two teachers at two public middle schools in the same district. One school was a public magnet school for science, mathematics, and technology, whereas the other was a neighborhood school. Both schools had populations that were over $90 \%$ African-American with large percentages of students participating in the free-lunch program.

These classrooms were part of a districtwide reform effort in science in conjunction with the Center for Learning Technologies in Urban Schools (LeTUS). LeTUS was a collaborative partnership between the University of Michigan, Detroit Public Schools, Northwestern University, and Chicago Public Schools. A goal of LeTUS was to infuse the use of effective learning technologies in Detroit and Chicago schools at a systemic level. To accomplish this goal, LeTUS utilized the framework of project-based science, using a combination of customdeveloped curricula, learning technologies, and coordinated professional development for middle school science teachers in urban settings (Blumenfeld, Fishman, Krajcik, Marx, \& Soloway, 2000; Singer et al., 2000). This was accomplished through a process of building on previous educational research and collaborating closely with teachers and administrators to adapt and create sustainable reform (Blumenfeld et al., 2000).

Both teachers participating in this study were female African-Americans. Ms. Tinsley ${ }^{1}$ had over 20 years of teaching experience in science. She had previous experience with project-based science, and she had used this project in her classroom three times prior to this study. During the study she followed the curriculum closely, and enacted all parts of the project. Ms. Holly was a second-year teacher and in the process of completing her master's degree in education during the semester in which the study took place. She was a strong believer in project-based instruction, and had used other LeTUS project-based units during the previous year. This was her first time using this particular curriculum unit. Ms. Holly attempted to follow the curriculum, but did make some modifications. These included changing the focus of one of the investigations to be more "fun" for students, and omitting one of the learning sets toward the end of the project due to time constraints.

\section{Instructional Context}

The 10-week curriculum unit that served as the focus for this study centered on the driving question, Why do I need to wear a helmet when I ride my bike? (Schneider \& HICE, 2001). This unit was designed following the framework of project-based science, and the specific contextualizing features were developed to align with the characteristics described above. The driving question of this unit was designed to lead students through an inquiry into the physics of collisions, including the development of science concepts such as motion, velocity, acceleration, 
and force. In addition, the driving question situated the project in a context familiar and important to many students - that of riding a bicycle and falling off.

Students experienced two anchoring events in the unit. At the beginning of the project students viewed a video of a young man talking about his serious bicycle accident while not wearing a helmet. Students also shared brief autobiographical stories about riding bikes, and if they were ever involved in an accident. Students and teachers frequently referred back to the video and personal stories over the course of the project. The second anchoring event was a demonstration. An unprotected egg rolled down a ramp in a cart, representing a student riding a bicycle. When the cart hit the end of the ramp and stopped, the egg flew out of the cart and broke on the table. Similar to the video viewed at the beginning of the project, the egg-and-cart demonstration was a common experience shared by all students in the class and served as an anchor to connect both science ideas and individual student experiences. The demonstration was supported by four questions that students responded to after they first observed the demonstration. The four questions were: (1) Describe what happened as the egg and the cart traveled down the ramp. Explain why this occurred. (2) Describe what happened to the egg and the cart when they reached the barrier. Explain why this occurred. (3) Describe what happened during the collision of the egg with the tabletop. Explain why this occurred. (4) Describe how the events of the collision would be changed by a helmet. Students returned to the egg-and-cart demonstration and the four questions periodically during the project and revised their responses based on their developing scientific understanding of the events in a collision.

The activities, investigations, and discussions that followed in the project were all related to the driving question and most utilized aspects of the anchoring events. Students used eggs, carts, and ramps to investigate force and Newton's First Law of Motion, and these materials were also used in conjunction with motion sensors to develop an understanding of velocity and acceleration. The egg-and-cart demonstration was also the focus of the final artifact, where students created and investigated a helmet for the egg to demonstrate their understanding of collisions. Students used motion sensors in their own investigation about the effectiveness of their helmet designs to protect the egg. In addition, students created an initial concept map of their understanding of a collision at the beginning of the unit. This concept map, along with the four questions regarding the egg-andcart demonstration, were revisited and elaborated multiple times over the course of the project as the students' understanding of the science behind a collision developed.

The project concluded with a final presentation by students to the class where they presented both the design of their egg helmet and the results of their investigations into its effectiveness for protecting the egg. The presentations were designed to support students as they integrated and applied their knowledge of collisions and investigations to the egg-and-cart demonstration. This event both unified the different activities and investigations conducted during the unit and brought closure to this extended project.

\section{Focus Students}

From each of the two study classrooms, six students (three boys, three girls) were selected as focus students. The selection process occurred in two phases. First, based on teacher recommendations, students from each classroom were preselected based on their being frequently present in class, achieving a $\mathrm{C}$ grade average or above academically, and being willing and open to talk with an interviewer. From these students, six from each class were randomly chosen as focus students. One focus student left Ms. Tinsley's class halfway through the project and his information was not included in the analyses in this study. The data collected from the five remaining focus students for her class are reported. 


\section{Methods}

The research reported here was part of a larger study to explore several aspects of contextualized instruction in project-based science. In addition to the analysis of classroom observations and learning assessments described, stimulated recall interviews with focus students were conducted and classroom observations were further analyzed for the use of contextualized instruction by teachers and students during enactment. These results are described elsewhere (Rivet, 2006; in review).

\section{Data Collection and Initial Data Preparation of Classroom Observations}

Target lessons were observed and videotaped in each classroom over the course of the project. Target lessons were ones in which the contextualizing features played a dominant role, and included the introductory lesson and the anchoring events, the introductions to benchmark lessons and inquiry activities, the wrap-up lessons where students integrated what they learned and related this back to the contextualizing situation, and the culminating final presentations for the project. We communicated with teachers in advance of enacting the identified contextualizing lesson and attempted to observe and videotape as many of these lessons as possible in each classroom. In all, 10 contextualizing lessons ( 11 and 12 class periods) were observed for each teacher for a total of 23 observed class periods, each approximately 50 minutes. During the videotaped observations the researcher focused on all students during whole-class discussions and demonstrations, and rotated among groups that included one or more of the focus students during small-group work. She attempted to observe each of the focus students in small-group settings an equal amount of time across the enactment.

Data preparation of the classroom observations involved creating detailed written descriptions of each class period from the videotaped observations, using a process consistent with that described by Schneider (2001). The descriptions focused particularly on student participation during class, including: (a) student conversations about the driving question or anchoring events ("It's like what happened to the egg when it fell from the cart"); (b) connections made by students between the science ideas and the contextualizing aspects of the project ("When I was riding and hit the tree branch, the branch was an unbalance force so I stopped"); and (c) prior knowledge and experiences (relevant or not) articulated by the students ("When we were riding down the small hill we went fast, but riding down the big hill, we went really fast" and "Is the motion because the forces were unbalanced?"). Whole-class and small-group discussions were described in detail. These running descriptions were between 4 and 7 pages long for each observed class period.

\section{Data Analysis of Classroom Observations}

The comments, conversations, and actions of each focus student were identified and summarized for the observed class periods. All instances when participation occurred by any of the focus students were highlighted, and short paragraphs were written that described the actions, comments, and contributions of each focus student for each observed class period. The paragraph also included information on the presence and accuracy of science concepts mentioned by the students in class discussion, small-group work, or class presentations. A rating metric (shown in Table 1) was developed to gauge students' participation during observed class periods in terms of their engagement with the contextualizing aspects of the project to support their learning, consistent with the method described by Lee and Brophy (1996). Each focus student was assessed a rating score based on the comments made during whole-class discussions and small-group work 
Table 1

Rating metric for focus student's use of contextualizing during classroom observations

\begin{tabular}{|c|c|c|}
\hline Rating Score & Description & Example \\
\hline 0 & - No evidence of class participation & No responses made in class \\
\hline 1 & $\begin{array}{l}\text { - One or two short, low-level } \\
\text { response/recall/examples } \\
\text { - Unrelated, trivial, off-task comments }\end{array}$ & $\begin{array}{l}\text { Asked if they needed to include } \\
\text { velocity and stuff during presenta- } \\
\text { tions; complained about the order of } \\
\text { group presentations }\end{array}$ \\
\hline 2 & $\begin{array}{l}\text { Three or more short, low-level } \\
\text { response/recall/examples }\end{array}$ & $\begin{array}{l}\text { Called on by teacher to review the } \\
\text { demonstration from a previous } \\
\text { class; provided examples of differ- } \\
\text { ent types of bikes }\end{array}$ \\
\hline 3 & $\begin{array}{l}\text { - One or two brief relational } \\
\text { comments } \\
\text { - One or two relational comments that } \\
\text { are elaborated but inaccurate } \\
\text { - One or two elaborated and accurate } \\
\text { comments, but other comments that } \\
\text { are inaccurate } \\
\text { - In presentations, makes several } \\
\text { inaccurate comments }\end{array}$ & $\begin{array}{l}\text { Stating that the cart gained speed as it } \\
\text { went down the ramp when watching } \\
\text { the egg-and-cart demonstration; } \\
\text { stating that a force kept pushing you } \\
\text { when your bike stopped so you fell } \\
\text { off (inaccurate) }\end{array}$ \\
\hline 4 & $\begin{array}{l}\text { - One or two relational comments that } \\
\text { are elaborated and mostly accurate } \\
\text { - Multiple brief relational comments, } \\
\text { mostly accurate } \\
\text { - In presentations, majority of comments } \\
\text { are accurate, but some are inaccurate }\end{array}$ & $\begin{array}{l}\text { Presentation of concept map included } \\
\text { explanation of ideas such as unba- } \\
\text { lanced forces can change motion } \\
\text { and velocity is distance over time } \\
\text { and depends on direction }\end{array}$ \\
\hline 5 & $\begin{array}{l}\text { - Three or more elaborated relational com- } \\
\text { ments } \\
\text { - Attempts to understanding relationships } \\
\text { between science and contextualizing fea- } \\
\text { tures } \\
\text { - Notable events }\end{array}$ & $\begin{array}{l}\text { Initiates class discussion by debating } \\
\text { with teacher and peers about } \\
\text { Newton's First Law, because, in } \\
\text { reality, friction acts against motion } \\
\text { to slow things down so a force needs } \\
\text { to be continually applied to keep an } \\
\text { object in motion }\end{array}$ \\
\hline
\end{tabular}

as well as actions noted in the observation transcript. To consistently rate individual participation of each student, when groups that included one of the focus students presented the results of their work but the focus student did not speak during the presentation, it was not included as a contribution by that student, even though they may have actively participated in the design of the work being presented.

Students received a rating of 0 when there was no noted participation during the class period. A rating of 1 or 2 was given when a student's comments were brief and indicated minimal engagement. Such comments included responses to the teacher's questions that involved simple recall such as review of earlier class events, or providing short examples like naming a type of bicycle. These comments were not elaborated by students, in terms of adding additional information or illustrating their thinking behind their response. A rating of 3 or 4 was given when a student's articulated a relationship between the science concepts under discussion and one of the contextualizing features of the Helmet project, the contextualizing theme of bike riding and bike accidents, or other personal or real-world examples. Such comments included applying the idea of 
Newton's First Law to explain why they fell off their bike in an accident or discussing the effects of friction on different types of roads. The difference between a score of 3 and 4 was determined in part by the extensiveness of the relational comments made during the class period and in part by the scientific accuracy of the concepts discussed by students. A score of 5 was given when a notable event occurred in class regarding one of the focus students that illustrated their attempts to understanding the relationships between the science ideas and the contextualizing features or realworld examples. Such events were infrequent during the observed lessons but reflected students' efforts to make meaning of both the science concepts themselves and their use to explain the world around them. Discussion of science content was also one of the criteria for assigning a rating of 5 to a focus student's participation during an observed lesson. Students' participation during contextualizing lessons that did not specifically address science concepts, such as the first lesson of the project when the driving question was introduced, were scored a maximum rating of 4 based on students' contributions during class discussions.

The classroom participation for each focus student was coded across the classroom transcripts using this rating metric. Another researcher rated a subset of the classroom transcripts and differences between scorers were discussed, resulting in reliability of over $90 \%$ between scorers. Scores were then averaged across the number of observed class periods for which each student was present.

\section{Contextualizing Scores for Focus Students}

The analysis of focus students' contributions during observed contextualizing lessons resulted in a contextualizing score for each focus student. This score reflects students' use of the contextualizing aspects of the Helmet project, including the driving question and contextualizing theme, the anchoring events, integration activities, and personal and real-world examples as they worked through the project and developed their understandings of the science concepts and applications. Table 2 displays the average contextualizing score and standard deviation across all observed class periods for each focus student. Students on the high end of the scale were observed on multiple occasions to verbalize links between the science ideas and the contextualizing aspects of the project and use the contextualizing features and other real-world examples to develop their understanding of the science ideas individually and relationships between ideas. Conversely, students on the low end of the scale were not observed to participate frequently in class, along with

Table 2

Contextualizing scores for focus students

\begin{tabular}{lcc}
\hline & Contextualizing Score & Standard Deviation \\
\hline Ms. Holly's students & & \\
Doug & 2.92 & 1.38 \\
Laura & 2.58 & 1.32 \\
Anita & 2.45 & 0.66 \\
Jake & 1.50 & 1.26 \\
Rene & 1.17 & 1.07 \\
Matt & 0.50 & 0.87 \\
Ms. Tinsley's students & & \\
Joe & 3.09 & 0.9 \\
Amy & 2.18 & 1.53 \\
Tori & 2.18 & 1.53 \\
Jay & 1.73 & 1.35 \\
Abby & 0.18 & 0.39 \\
\hline
\end{tabular}


students who did participate but did not express attempts to link the contextualizing features and the science ideas.

The possible contextualizing scores ranged from 0 , indicating no student participation during the observed class periods, to 5, indicating the highest rating of student's use of contextualizing features possible during all observed class periods for that student. As can be seen in Table 2, students ranged in their use of the contextualizing features to support their learning from 0.18 to 3.09. There were 2 of the 11 focus students, one from each study classroom, who received a contextualizing score of less than 1 . The lowest of these, Abby, also had a very small standard deviation in her score. This indicates that during the majority of the observed class periods, she did not participate in such a way as to indicate her use of the contextualizing features in the Helmet project. This analysis is unable to distinguish if she and other students who received low scores were considering the contextualizing features as they learned about the science concepts introduced in this project but did not vocalize this thinking during class, or if indeed these students were not engaged with either the contextualizing aspects of the project or science learning in general. This is a limitation of this analysis method that relies on observed student actions and participation during class to assess the use of contextualizing features as supports for learning.

Likewise, it is also notable that the contextualizing scores, which were averaged across observed class periods, resulted in scores that fell in the lower to middle portion of the possible range. There are two possible reasons for this result. First, although theoretically it was possible for a focus student to be observed making meaning of the science concepts in terms of the contextualizing features during all of the observed lessons, in practice this was not the case. A rating of 5 was given only for notable events that occurred in the classroom when significant meaning-making was demonstrated through class discussions or presentations, and such events occurred infrequently in the observed lessons. A second explanation is that even students who were rated highest in terms of their observed use of the contextualizing aspects to support their learning were not observed doing so during every observed class period. There were class periods when even these students were quiet and did not participate frequently. Given these issues, it is reasonable to consider the scores achieved by these focus students as appropriate reflections of their participation and use of the contextualizing features.

\section{Assessments of Student Learning}

To explore the relationship between students' use of the contextualizing aspects of instruction and science learning, students' learning was assessed via two assessments: an individual pre/ posttest administered to all students participating in the Helmet project; and evaluation of two artifacts completed as part of the assessment of the project. Students' performance on these assessments was compared with their contextualizing score to explore the relationship between students' use of the contextualizing aspects of the project for learning and their demonstrated understanding of the science ideas.

\section{Pre/Posttest Assessment Measure}

A pre/posttest measure was used to assess learning of the science content and process skills introduced in the project (Marx et al., 2004) for all students in participating teachers' classrooms. The pre/posttest measure consisted of 18 multiple-choice items and 2 short response items, with a maximum possible score of 24 possible points. Items were created to measure both content and process understanding across three cognitive levels-low, medium, and high. Low items focused on recall of information, definitions and understanding of information. Medium-level items 
involved drawing simple relationships, translating between representations (such as between a data table and a graph), and applying knowledge to new situations. High cognitive items were all short-answer responses items that required students to create hypotheses, describe and analyze data, draw conclusions, and use concepts to explain real-world phenomena.

Specifically, understanding was assessed for three science learning goals of force, velocity, and impulse. The learning goal of force included the science concepts of Newton's First Law, balanced and unbalanced forces, and their effect on motion. The learning goal of velocity included the science concepts of speed as distance per unit time, velocity defined as speed and direction, change in velocity due to forces such as gravity, and the representation of velocity in motion-time graphs. The learning goal of impulse included the descriptive relationship between velocity, force, stopping time, and stopping distance during impact. The learning goals of force and velocity were assessed though three to four multiple-choice items at low and medium cognitive levels. The learning goal of impulse was assessed through both four multiple-choice items at low and medium cognitive levels as well as one short-response, high-cognitive-level item (see Appendix for an example of assessment items at each of these three levels). The pre/posttest assessment also addressed student understanding of inquiry process skills, including conducting investigations, interpreting graphs, and writing conclusions supported by evidence, through multiple-choice items at low and medium cognitive levels as well as a short-response, high-cognitive-level item.

Correct responses were tallied for the multiple-choice items. Rubrics were created for openended items, and interrater reliability was established at $90 \%$ or better between scorers. The pre/ posttest data were organized and sorted to include only those students who had completed both the pretest and posttest for each enactment. Matched two-tailed $t$-test analyses were conducted to compare the pretest and posttest results in terms of overall improvement and gains for each of the science learning goals of the project.

The overall pre/posttest results for all Detroit Public School students who participated in the Helmet project during the Fall 2001 semester ( $\mathrm{N}=523$ for match pre/posttests), as well as results from students in all classes taught just by Ms. Holly and Ms. Tinsley, are shown in Table 3. Effect size is reported as a convenient standardized metric for evaluating the strength of student gains in

Table 3

Overall achievement and achievement by learning goal for pre/posttest assessment

\begin{tabular}{lcccc}
\hline & Pretest Mean $(S D)$ & Posttest Mean $(S D)$ & Gain $(S D)$ & Standard Effect \\
\hline Overall $(\mathrm{N}=523)$ & & & & \\
Total (24) & $7.55(2.55)$ & $9.77(3.30)$ & $2.21(3.23)$ & $0.87^{\text {a**** }}$ \\
Force (4) & $1.19(0.86)$ & $1.80(1.03)$ & $0.61(1.17)$ & $0.71^{* * * *}$ \\
Velocity (5) & $2.46(1.02)$ & $2.96(1.13)$ & $0.50(1.38)$ & $0.49^{* * * *}$ \\
Impulse (7) & $1.62(1.04)$ & $1.99(1.17)$ & $0.37(1.47)$ & $0.36^{* * * *}$ \\
Ms. Holly (N=43) & & & & \\
Total (24) & $9.72(2.44)$ & $11.86(2.79)$ & $2.14(2.97)$ & $0.88^{* * * *}$ \\
Force (4) & $1.26(0.58)$ & $2.12(0.93)$ & 0.86 & $1.48^{* * * *}$ \\
Velocity (5) & $3.05(0.79)$ & $3.30(1.01)$ & 0.25 & 0.32 \\
Impulse (7) & $1.98(0.96)$ & $2.09(0.89)$ & 0.11 & 0.11 \\
Ms. Tinsley (N=49) & & & \\
Total (24) & $8.06(1.99)$ & $11.29(3.08)$ & $3.23(2.83)$ & $1.62^{* * * *}$ \\
Force (4) & $1.20(0.91)$ & $2.29(1.08)$ & 1.09 & $1.20^{* * * *}$ \\
Velocity (5) & $2.47(1.00)$ & $2.90(1.23)$ & 0.43 & $0.43^{*}$ \\
Impulse (7) & $1.80(1.06)$ & $2.04(1.06)$ & 0.24 & 0.23 \\
\hline
\end{tabular}

${ }^{\mathrm{a}}$ Number of items for each scale/subscale.

**** $p<0.001$.

${ }^{*} p<0.05$. 
large populations across the various student groups. The effect size indicates the average gain on the posttest measured in pretest standard deviation units. To aid interpretation, Cohen (1988) offered conventional definitions for the effect size $(E S)$ as small $(E S=0.2)$, medium $(E S=0.5)$, and large $(\mathrm{ES}=0.8)$. ESs for total scores presented in what follows were all statistically significant $(p<0.001)$; however, not all of the subscales for the individual teachers were statistically significant.

These results indicate that Ms. Holly's students initially had higher-than-average scores on the pretest measure but showed improvement in a similar fashion to the average achievement by other classes participating in the Helmet project. Ms. Tinsley's students scored similarly to the average on the pretest measure but achieved higher-than-average gains. There could be several potential explanations for this result, including the fact that Ms. Tinsley had previous experience working with this particular project and the majority of her students had participated in at least one of these types of projects in other science classes they had taken. The fact that Ms. Tinsley also enacted all parts of the project, whereas Ms. Holly skipped Learning Set 4 and did not extensively introduce the concept of impulse during her enactment, may also have contributed to this result.

Although not all of the effect sizes for each of the learning goals were statistically significant, it is notable that both overall and for each of the two study teachers that posttest gains were highest for the questions related to the learning goal for force and lowest for the questions related to the learning goal for impulse. These results correspond to the extent of the contextualizing observed in the two study teachers' classrooms. Concepts related to the learning goal of force, including Newton's First Law, balanced and unbalanced forces, and the effect of force on motion were highly contextualized, whereas concepts related to velocity and changing velocity were comparatively less contextualized and relatively little contextualizing occurred around concepts relating to impulse. This may indicate that the curriculum materials provided more support for the contextualization of ideas related to force that were presented earlier in the project and less support as the project progressed when students investigated ideas related to velocity and impulse. An alternative explanation, however, could also be related to content coverage and the level of complexity of the ideas. In both of the observed classrooms, teachers spent more classroom time exploring ideas related to force, which is a relatively less complicated idea; less time exploring ideas related to velocity, which is a more difficult concept for students to grasp; and the least amount of project time exploring ideas related to impulse, which is considered the most complicated science concept presented in the project.

\section{Student Artifacts}

In addition to students' egg helmet designs, which were presented and explained during the final presentations, students expressed their understanding of the science concepts through two other artifacts used as assessments for the project: the concept maps and the four questions related to the egg-and-cart demonstration. Students iteratively revised both of these artifacts at multiple points throughout the project. The concept maps were developed as group artifacts in both classrooms. The four questions were intended to be completed individually and Ms. Holly used them in this way. However, Ms. Tinsley opted to have students complete the four questions as a group activity as well. The results of the evaluation of the final version of these artifacts are shown in Table 4.

The final concept maps for each group that included at least one of the focus students were assessed with respect to the accuracy of the science concepts and links between ideas for each of the learning goals for the Helmet project. The following scheme was used to guide the rating of the final concept maps: high (3)—most ideas present, accurately organized, interconnecting links; medium (2)—some ideas present, accurately organized, few interconnecting links; low (1)—ideas 
Table 4

Evaluation of the final versions of the concept maps and four questions

\begin{tabular}{|c|c|c|c|c|c|c|}
\hline \multirow[b]{2}{*}{ Student } & \multicolumn{3}{|c|}{ Concept Map } & \multicolumn{3}{|c|}{ Four Questions } \\
\hline & Force & Velocity & Impulse & Force & Velocity & Impulse \\
\hline Anita & 3 & 3 & 1 & 1 & 3 & 1 \\
\hline Doug & 1 & 1 & 1 & 1 & 3 & 1 \\
\hline Jake & 2 & 1 & 1 & 1 & 1 & 1 \\
\hline Laura & 3 & 3 & 1 & 3 & 2 & 1 \\
\hline Matt & 2 & 2 & 1 & NA & NA & NA \\
\hline Rene & 2 & 2 & 1 & NA & NA & NA \\
\hline Abby & 2 & 2 & 1 & 1 & 1 & 1 \\
\hline Amy & 2 & 2 & 1 & 2 & 3 & 1 \\
\hline Jay & 2 & 2 & 1 & 1 & 3 & 1 \\
\hline Joe & 2 & 2 & 1 & 2 & 3 & 1 \\
\hline Tori & 2 & 2 & 1 & 1 & 2 & 1 \\
\hline
\end{tabular}

missing or inappropriate ideas present, not accurately organized, no links. Reliability for this rating scheme was established with another researcher, with an agreement above $90 \%$. One group in each classroom included two focus students: Rene and Matt worked together in Ms. Holly's class, and Amy and Joe worked together in Ms. Tinsley's class. Each of these focus students received the same rating for their final group concept map.

The final versions of the four questions were assessed for the appropriateness of the description of the demonstration and the accuracy of the scientific explanation written by the students. To review, the four questions were as follows: (1) Describe what happened as the egg and the cart traveled down the ramp. Explain why this occurred. (2) Describe what happened to the egg and the cart when they reached the barrier. Explain why this occurred. (3) Describe what happened during the collision of the egg with the tabletop. Explain why this occurred. (4) Describe how the events of the collision would be changed by a helmet. As such, Question 1 addressed the velocity learning goal for the Helmet project, Question 2 addressed the force learning goal, and Questions 3 and 4 addressed the impulse learning goal. The responses to each question were rated using the following scheme: high (3)—complete and mostly accurate; medium (2)—semicomplete and/or partially accurate; low (1) - incomplete and/or mostly inaccurate. Reliability was established with another researcher, with an agreement of $88 \%$. Responses for Rene and Matt from Ms. Holly's class were not accessible at the end of the project. Ms. Tinsley's students, Amy and Joe, who worked together in a group, were each given the same rating for their responses.

The analysis of these two artifacts reflects the extent of ideas covered in each classroom as well as the extent of contextualizing for each of these ideas. As shown in Table 4, these results illustrate that the learning goal of impulse was not addressed in Ms. Holly's classroom and indicates that it was not clearly understood by students in Ms. Tinsley's classroom. Most students did not include concepts relating to impulse in their final concept maps, and the few who did include these ideas did so inaccurately. Students' responses to Questions 3 and 4 did not include scientific explanations of the egg-and-cart demonstration related to impulse. However, more students did address concepts related to the learning goals of force and velocity accurately and completely in the final versions of their concept maps and four question responses.

\section{Contextualizing Instruction and Student Learning}

This study explored the relationship between students' use of the contextualizing aspects during project-based instruction and their learning of important science concepts. To consider this 
relationship, we compared the contextualizing scores for the 11 focus students with their performance on the assessment measures. Given that Ms. Holly's class did not address the concept of impulse during their enactment, the assessment results for this learning goal were not included in the analysis for either class. In this analysis, the results of each assessment type were considered individually in comparison to the contextualizing scores. Then the results of the assessments were normalized and combined to give a total learning score, which was then compared with students' contextualizing score to explore possible relationships between their use of the contextualizing aspects of the project and their performance on these measures of learning.

\section{Comparing Contextualizing Scores and Pre/Posttest Performance}

The pre/posttest assessment measure consisted of four multiple-choice items that addressed the learning goal of force and five multiple-choice items that addressed the learning goal of velocity. The total possible range in gain scores for these two learning goals was -9 to $9 .^{2}$ Therefore, 9 was added to each number to remove the negative values, resulting in a transformed possible gain score with the range of $0-18$. The results of this transformation are shown in Table 5 .

To explore the relationship between focus students' use of the contextualizing features during instruction and their performance on the pre/posttest measure, correlations were calculated examining their contextualizing scores from Table 2 and transformed pre/posttest gains scores. A graphical representation of this analysis is displayed in Figure 1. The results indicate a significant correlation between the two $(r=0.61, p=0.05)$ with $37 \%$ of the variance in students' pre/posttest gain scores predicted by their use of the contextualizing features during instruction.

The graphical representation of this analysis illustrates that those students observed in class relating both their personal experiences and the science concepts to the driving question, anchoring events, and overall contextualizing theme of the project appeared to have a stronger performance on the pre/posttest assessment. Likewise, students who were not observed engaging with the contextualizing features of the project during classroom observations did not achieve strong pre/posttest gains.

Table 5

Standardized results for pre/posttest gains and total student artifact scores, and total learning score

\begin{tabular}{lccccccc}
\hline Student & $\begin{array}{c}\text { Transformed } \\
\text { Pre/Post } \\
\text { Gain Scores }\end{array}$ & $\begin{array}{c}\text { Pre/Post } \\
z \text {-Scores }\end{array}$ & $\begin{array}{c}\text { Positive } \\
\text { Pre/Post } \\
z \text {-Scores }\end{array}$ & $\begin{array}{c}\text { Total } \\
\text { Artifact } \\
\text { Score }\end{array}$ & $\begin{array}{c}\text { Artifact } \\
z \text {-Scores }\end{array}$ & $\begin{array}{c}\text { Positive } \\
\text { Artifact } \\
z \text {-Scores }\end{array}$ & $\begin{array}{c}\text { Total } \\
\text { Learning } \\
\text { Score }\end{array}$ \\
\hline Anita & 12 & 0.76 & 2.65 & 10 & 1.28 & 2.83 & 5.48 \\
Doug & 13 & 1.21 & 3.1 & 6 & -0.98 & 0.57 & 3.67 \\
Jake & 9 & -0.56 & 1.33 & 5 & -1.55 & 0.00 & 1.33 \\
Laura & 13 & 1.21 & 3.1 & 11 & 1.86 & 3.41 & 6.51 \\
Matt & 8 & -1.01 & 0.88 & 7 & -0.41 & 1.14 & 2.02 \\
Rene & 8 & -1.01 & 0.88 & 7 & -0.41 & 1.14 & 2.02 \\
Abby & 10 & -0.12 & 1.77 & 6 & -0.98 & 0.57 & 2.34 \\
Amy & 10 & -0.12 & 1.77 & 9 & 0.72 & 2.27 & 4.04 \\
Jay & 6 & -1.89 & 0 & 8 & 0.15 & 1.70 & 1.70 \\
Joe & 11 & 0.32 & 2.21 & 9 & 0.72 & 2.27 & 4.48 \\
Tori & 13 & 1.21 & 3.1 & 7 & -0.41 & 1.14 & 4.24 \\
\hline
\end{tabular}

Transformed pre/post gain score mean $=10.27$, standard deviation $=2.26$; total student artifact score mean $=7.72$, standard deviation $=1.76$. 


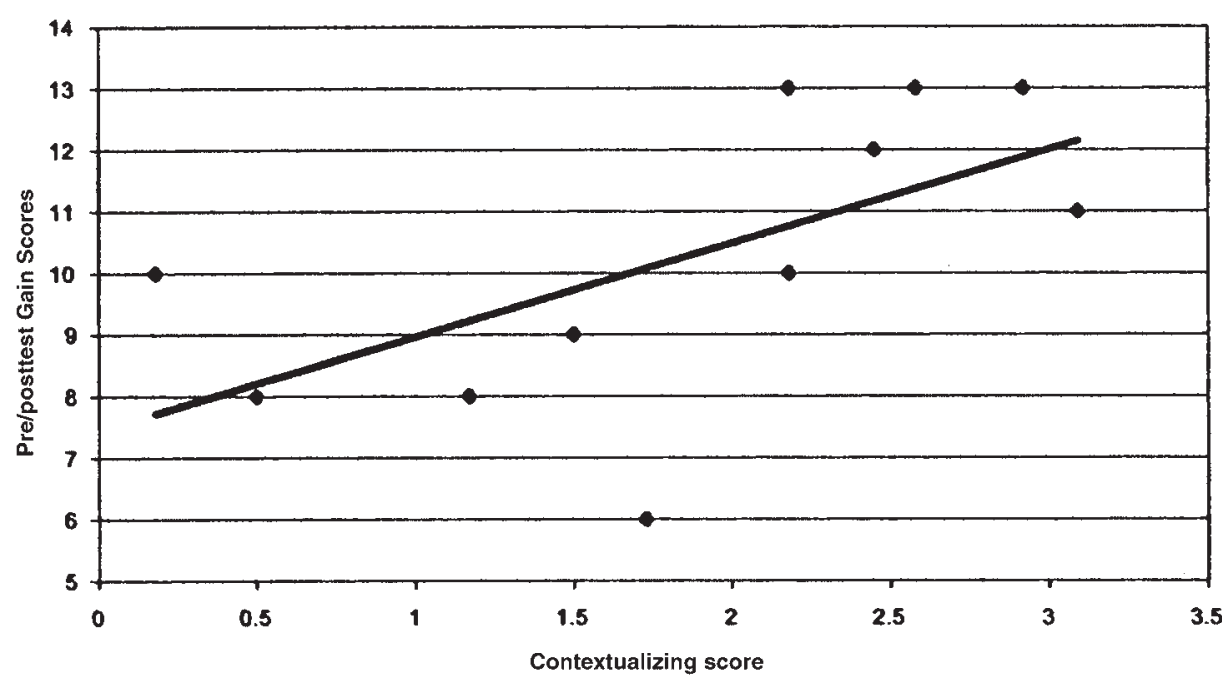

Figure 1. Graphical representation of the correlation between focus students' contextualizing scores and pre/posttest gain scores.

\section{Comparing Contextualizing Scores and Student Artifact Results}

The results of the analysis of the two student artifacts in the areas of force and velocity were combined to give an overall rating for these assessments. The learning goal score for each assessment ranged from 1 (low) to 3 ( $h i g h$ ), with a possible range for the total combined score of 4-12. The final responses to the four questions for two focus students, Rene and Matt, were not available for collection at the end of the project. These students received the mean score of the other students' performance in the areas of force and velocity for that artifact, rounded to the closest whole number. Students' overall scores on the student artifacts are displayed in Table 5.

To explore the relationship between focus students' use of the contextualizing features during instruction and their performance on these assessment artifacts, correlations were calculated examining students' contextualizing scores, as shown in Table 2, and total artifacts scores. A graphical representation of this analysis is displayed in Figure 2. The results indicate a correlation between the two $(r=0.51, p=0.11)$, with $26 \%$ of the variance in students' artifacts scores predicted by use of the contextualizing features during instruction.

Although not significant, the results of this analysis indicate an overall positive correlation of the contextualizing score as a predictor for performance on student artifacts. When comparing this result to that of the correlation of contextualizing scores with pre/posttest gains, both analyses show relatively strong correlations.

\section{Comparing Pre/Posttest and Student Artifact Assessments}

The two assessments just described measure different ways that students expressed their learning. The multiple-choice items on the pre/posttest assessment, which was the most consistent assessment across students, focused primarily on the recall of information and definitions and the application of concepts to new settings. The concept maps and responses to the four questions, on the other hand, provided students with the opportunity to express and apply their understanding of the concepts in their own words, which was not afforded by the standardized pre/posttest measure for the learning goals of force and velocity. 


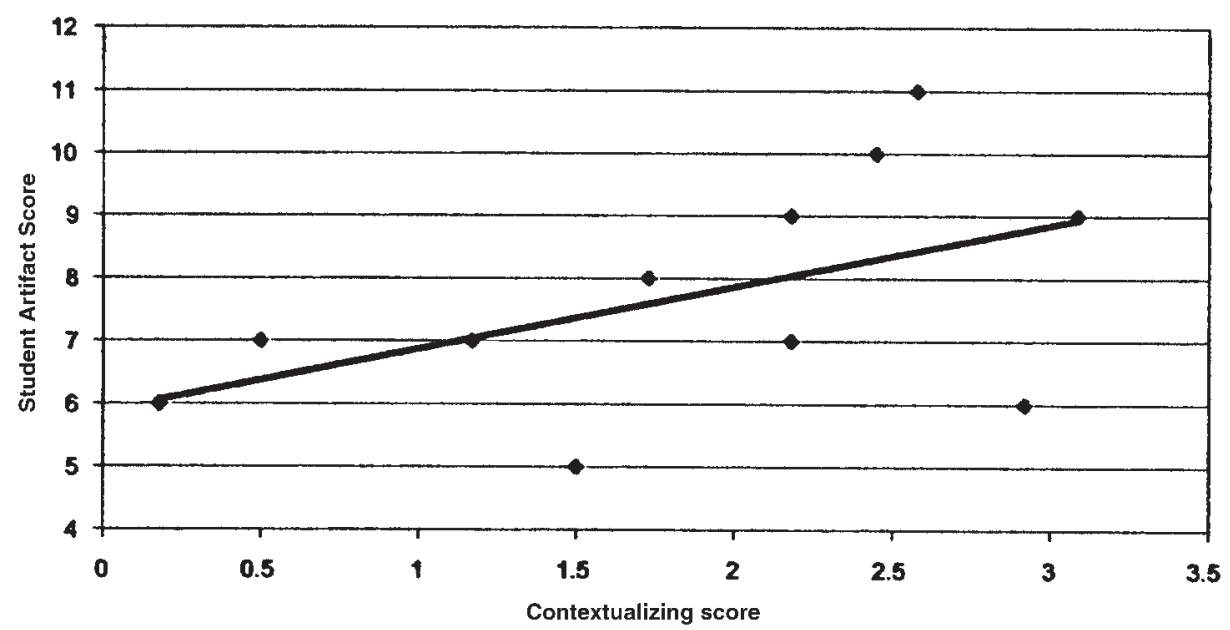

Figure 2. Graphical representation of the correlation between focus students' contextualizing scores and student artifact scores.

It is possible that some students were able to respond accurately to the low- and mediumcognitive-level multiple-choice items, but had not fully developed an understanding of the science concepts to accurately represent them on a concept map or apply them to explain the egg-and-cart demonstration. For example, Doug received a pre/posttest gain score of 13 out of 18 possible points, one of the highest scores of all of the focus students. However, he received a score of 5 out of 12 possible points on the student artifacts assessment for force and velocity. His artifacts indicated that he held misconceptions, such as velocity increasing only as one traveled downhill and friction as an immediate force that acted to stop moving an object suddenly, like jamming on the brakes in a car. This indicates that, although Doug performed well on the pre/posttest assessment measure, his performance on the student artifacts assessment appears to be a more accurate representation of his actual understanding of the science concepts addressed in the Helmet project.

It is also important to consider that, although the pre/posttest was an individual assessment, the concept maps and responses to the four questions were primarily completed in small groups. Depending on the focus students' role during group work, the artifacts may not be a reflection of their own understanding but that of another, perhaps more dominant, group member. For example, Jay received the lowest gain score on the pre/posttest measure of all the focus students but scored 9 out of a possible 12 points for the student artifacts. Classroom observations focused on his small-group work and group presentations illustrated that his group was primarily dominated by another student who was active in class and demonstrated accurate understandings of the science concepts in her responses and contributions to class discussions. When Jay presented group work to the class he made frequent errors and deferred to his group members for help halfway through his presentation. This indicates that his score for the student artifacts was likely influenced by his other group members' performance and the posttest assessment is a more accurate reflection of his understanding of the science concepts.

Given these differences in the ways that learning is assessed by the two measures, consideration of both assessments appears to be valuable and necessary to ascertain the extent and depth of students' science learning. For this reason, correlations were calculated to examine the results of the two assessments. The results indicate a slight correlation between the two 


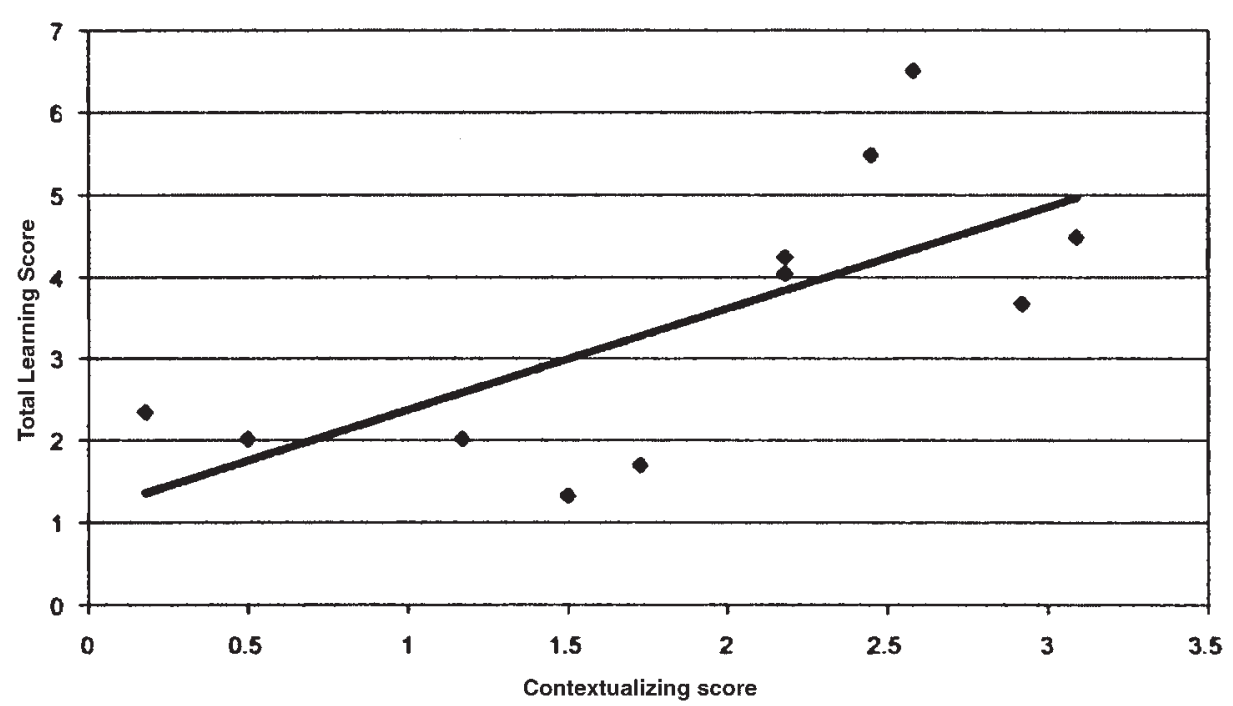

Figure 3. Graphical representation of the correlation between focus students' contextualizing scores and total learning scores.

assessments $(r=0.29, p=0.38$ ), with $9 \%$ of the variance in the artifact score predicted by students' performance on the pre/posttest measure. This analysis demonstrates that, although the pre/posttests and student artifacts measured different ways that students expressed their learning, there does appear to be a relationship for students who accurately demonstrate their understanding through higher pre/posttest gains to also accurately reflect their learning in the development of student artifacts. This information, in conjunction with the argument presented earlier for the need for evaluation of both assessments to fully ascertain students' science learning, justify the development of a total learning score that combines equally the results of these two measures.

To combine the results of the pre/posttest gains and student artifacts assessments, the results were first normalized. This was completed by first performing a linear transformation that consisted of dividing the difference from the mean by the standard deviation to determine corresponding $z$-scores for each set of results. A second linear transformation was conducted to remove negative values by adding the lowest score to each of the $z$-scores. For the pre/posttest results, the lowest $z$-score was -1.89 , so +1.89 was added to each of the scores to provide positive results. Similarly, for the student artifact scores, the lowest $z$-score was -1.55 so +1.55 was added to each of these scores. These normalized assessment scores were then added to determine a total learning score for each focus student. This total learning score weighed equally students' performance on the pre/posttest assessment and the two student artifacts, and provided a measure of students' overall demonstrated learning after participating in the Helmet project. The results of this process for the transformed pre/posttest gain scores, total student artifact scores, and total learning scores are displayed in Table 5.

\section{Correlation Between Contextualizing Scores and Total Learning Score}

To explore the relationship between focus students' use of the contextualizing features during instruction and their science learning, correlations were calculated to examine their 
contextualizing scores, as shown in Table 2, and the total learning scores displayed in Table 5. A graphical representation of this comparison is displayed in Figure 3. The results indicate a significant correlation between them $(r=0.70, p=0.02)$, with $48 \%$ of the variance in students' learning scores predicted by their use of the contextualizing features during instruction.

Not only is there a significant correlation between students' contextualizing scores and total learning scores, but it is also higher than the contextualizing score correlated with either of the two assessments individually. This result demonstrates the strong association when considering students' use of the contextualizing features during instruction along with their performance on these two different but related measures of learning.

\section{Discussion}

This study has established the presence of a strong correlation between students' use of contextualizing features in middle school project-based science classrooms and learning outcomes. The results of this work provide preliminary evidence regarding the power of contextualizing instruction in science classrooms to support student learning. Although the correlation between the contextualizing score and learning score does not indicate a causal relationship between the two, it is of interest to consider these results in light of the theoretical arguments for the proposed benefits of contextualizing instruction. Contextualizing instruction is proposed to support learning by providing a cognitive framework onto which students can connect or "anchor" ideas (CTGV, 1992a; Kozma, 1991). The use of meaningful real-world problems makes the learning situation "bushier" (Kozma, 1991), with more available links to connect information and relationships between new science concepts, prior knowledge and experiences, and real-world examples. From this perspective, the correlation seems to provide support for these ideas and suggests that contextualizing features, when actively used by students during instruction, may result in more learning by these students. It is particularly impressive that this relationship holds when the results of the two learning assessments are combined. This result thus provides strong evidence for the role that contextualizing instruction may play in supporting student science learning, and indicates the importance of facilitating students' active use of the contextualizing features during instruction.

An alternative explanation for this relationship is that contextualizing instruction primarily functions as a vehicle to motivate and engage students with the learning task (Blumenfeld et al., 1997; CTGV, 1997; Lave \& Wenger, 1991). Through engaging tasks that have meaning to students, such as the problems and situations utilized in contextualizing instruction, students are believed to be more engaged and more focused on the activities (Anderson, Reder, \& Simon, 1996; Blumenfeld et al., 1997; Brown et al., 1989; CTGV, 1992a). Several studies have demonstrated the relationship between involving students in authentic learning tasks that are relevant beyond the classroom and students' engagement in the learning process, and has been shown to be a powerful contributor to student self-reported engagement with instruction (Marks, 2000). However no studies have directly investigated the relationship between students' interest in the instructional context and their academic achievement (Krapp, Hidi, \& Renninger, 1992).

Although the results of this study do not clearly provide support for one or the other of these two theories regarding the relationship between contextualizing instruction and student learning, they do demonstrate a strong correlation between students' active use of contextualizing features during instruction and their performance on assessments for learning. This indicates 
that that students' use of the contextualizing features during instruction likely does more than engage students with the learning task, but also provides cognitive supports for students to differentiate, connect, and organize ideas (Linn, 2000). This follows the recommendations of Blumenfeld and colleagues (1991), who argued that fostering interest through instruction is not sufficient to support learning. Rather, the learning situation must not only motivate students but also promote students' thoughtful consideration of the science ideas and relationships. Based on the results of this analysis, it appears from this study that contextualizing instruction plays a powerful role in facilitating student learning through both motivational and cognitive means.

It is important to consider that this analysis was conducted with only eleven cases. As this study was a preliminary exploration into the use of contextualizing instruction in classrooms and its relationship to student learning, it was not designed to consider large numbers of students during classroom observations or collection of student artifacts. The correlation between the contextualizing score and learning score determined in this analysis may be strongly influenced by individual students' contributions and not an accurate reflection of larger populations. In addition, other classroom factors may have influenced these results, including the specific project-based curriculum materials used in these classrooms and teachers' interpretations of these materials, other teaching methods and techniques used by the teachers throughout the project's enactment, individual students' goals and focus in science class, and other classroom or school factors not explored in this study. However, these initial results are significant in that they provide preliminary evidence to support arguments regarding the role that contextualizing instruction can play in student learning of important science concepts.

Although future research is needed to elaborate and substantiate the results, this study illustrates the importance of considering the use of contextualizing instruction in the design of learning environments. While we do not fully understand how contextualizing instruction functions in classrooms to provide cognitive support for learning, these findings provide initial evidence for contextualizing instruction in science classrooms as a means to facilitate students' developing understandings of challenging science concepts. The results indicate the importance of contextualizing instruction in science learning environments and support recommendations for this instructional method to be considered as a significant aspect of the design of middle school project-based science learning environments supported by professional development efforts. Further research in this area will better our understanding of how to capitalize on students' experiences and real-world examples to leverage and facilitate effective learning.

\section{Notes}

${ }^{1}$ All teacher and student names are pseudonyms.

${ }^{2}$ Four items on the pre/posttest were related to concepts of force. A minimum gain score of -4 could be achieved if a student scored all items correctly on the pretest and all the same items incorrectly on the posttest. A maximum gain score of 4 could be achieved if students scored all items incorrectly on the pretest and all items correctly on the posttest. The same is true for the five items related to the concept of velocity.

The authors thank Ron Marx and our colleagues at the Center for Highly Interactive Computing in Education at the University of Michigan for their support of this research. 
Appendix A

Assessment Items for the Helmet Project

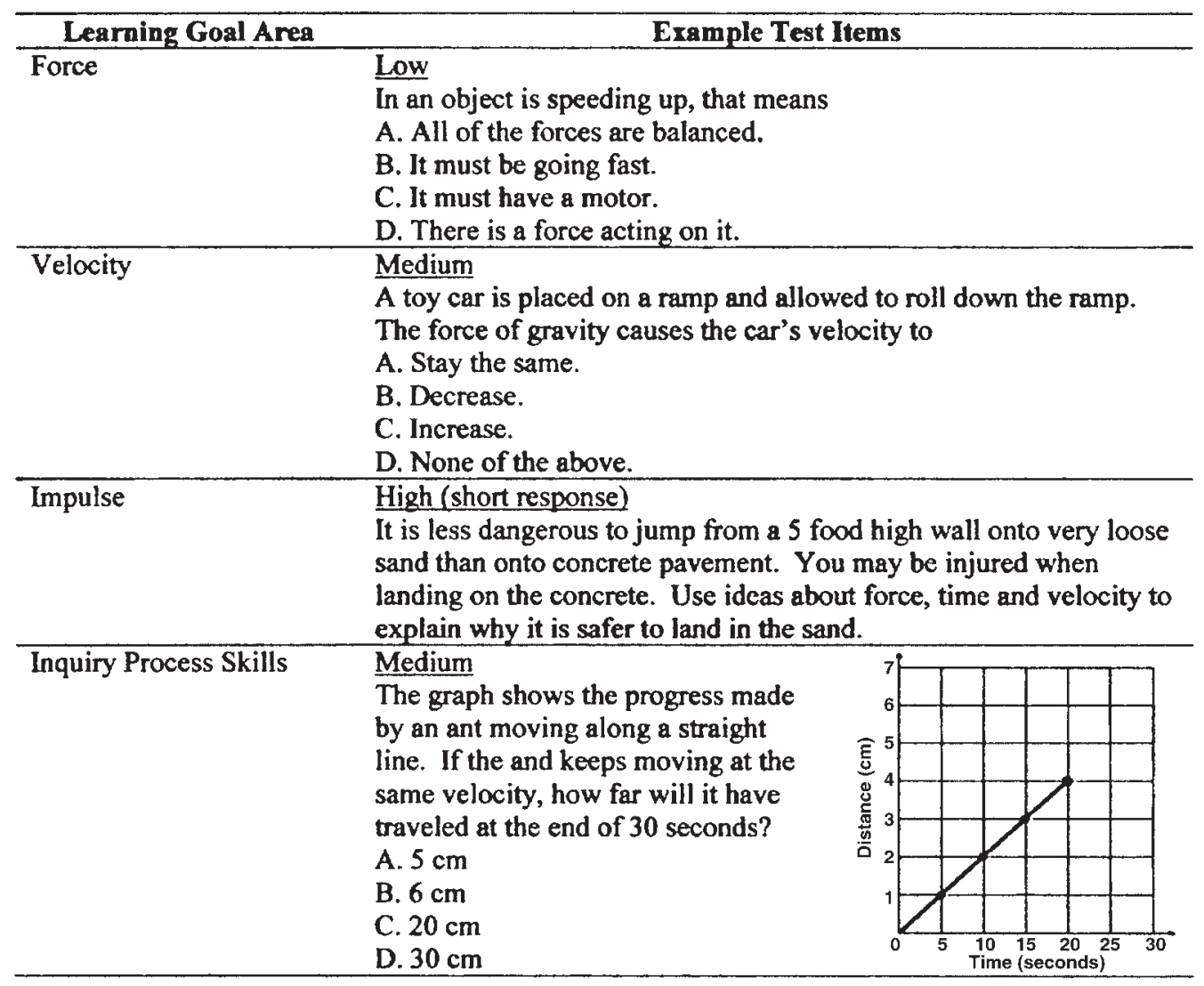

\section{References}

Anderson, J.A., Reder, L.M., \& Simon, H.A. (1996). Situated learning and education. Educational Researcher, 25, 5-11.

Blumenfeld, P.C., Fishman, B.J., Krajcik, J., Marx, R.W., \& Soloway, E. (2000). Creating usable innovations in systemic reform: Scaling up technology-embedded project-based science in urban schools. Educational Psychologist, 35, 149-164.

Blumenfeld, P.C., Marx, R.W., Patrick, H., Krajcik, J., \& Soloway, E. (1997). Teaching for understanding. In: B.J. Biddle, T.L. Good, \& I.F. Goodson (Eds.). International handbook of teachers and teaching (vol. 2 pp. 819-878). Dordrecht: Kluwer Academic.

Blumenfeld, P.C., Soloway, E., Marx, R.W., Krajcik, J.S., Guzdial, M., \& Palincsar, A. (1991). Motivating project-based learning: Sustaining the doing, supporting the learning. Educational Psychologist, 26, 369-398.

Bouillion, L.M., \& Gomez, L.M. (2001). Connecting school and community with science learning: Real world problems and school-community partnerships as contextual scaffolds. Journal of Research in Science Teaching, 38, 878-898. 
Brophy, J. (1998). Motivating students to learn. Boston: McGraw-Hill.

Brown, J.S., Collins, A., \& Duguid, P. (1989). Situated cognition and the culture of learning. Educational Researcher, 18, 32-42.

Cognition and Technology Group at Vanderbilt. (1992a). Anchored instruction in science and mathematics: Theoretical basis, developmental projects, and initial research findings. In: R. Duschl, \& R. Hamilton (Eds.). Philosophy of science, cognitive psychology and educational theory and practice (pp. 244-273). New York: SUNY Press.

Cognition and Technology Group at Vanderbilt. (1992b). The Jasper series as an example of anchored instruction: Theory, program description, and assessment data. Educational Psychologist, 27, 291-315.

Cognition and Technology Group at Vanderbilt. (1997). The Jasper Project: Lessons in curriculum, instruction, assessment, and professional development. Mahwah, NJ: Lawrence Erlbaum.

Cohen, J. (1988). Statistical power analysis for the behavioral sciences. Hillsdale, NJ: Lawrence Erlbaum.

Collins, A., Brown, J.S., \& Holum, A. (1991). Cognitive apprenticeship: Making thinking visible. American Educator (Winter), 6-11, 38-48.

Doyle, W. (1983). Academic work. Review of Educational Research, 53, 159-199.

Edelson, D.C., Gordin, D.N., \& Pea, R.D. (1999). Addressing the challenges of inquiry-based learning through technology and curriculum design. The Journal of the Learning Sciences, 8, 391-450.

Fusco, D. (2001). Creating relevant science through urban planning and gardening. Journal of Research in Science Teaching, 38, 860-877.

Hmelo, C.E., Holton, D.L., \& Kolodner, J.L. (2000). Designing to learn about complex systems. The Journal of the Learning Sciences, 9, 247-298.

Kolodner, J.L., Crismond, D., Gray, J., Holbrook, J., \& Puntambekar, S. (1998). Learning by design from theory to practice. In A.S. Bruckman, M. Guzdial, J.L. Kolodner, \& A. Ram (Eds.), Proceedings of ICLS98: International Conference of the Learning Sciences, Atlanta, GA, December 16-19, 1998 (pp. 16-22). Charlottesville, VA: AACE.

Kozma, R.B. (1991). Learning with media. Review of Educational Research, 61, $179-212$.

Krajcik, J., Blumenfeld, P.C., Marx, R.W., \& Soloway, E. (1994). A collaborative model for helping middle grade science teachers learn project-based instruction. The Elementary School Journal, 94, 483-497.

Krajcik, J., Czerniak, C., \& Berger, C. (2002). Teaching science in elementary and middle school classrooms: A project-based approach (2nd ed.). Boston: McGraw-Hill.

Krapp, A., Hidi, S., \& Renninger, K.A. (1992). Interest, learning, and development. In: A. Krapp, \& S. Hidi, \& K.A. Renninger (Eds.). The role of interest in learning and development. Hillsdale, NJ: Lawrence Erlbaum.

Land, S.M. (2000). Cognitive requirements for learning in open-ended learning environments. Educational Technology Research and Development, 48, 61-78.

Lave, J., \& Wenger, E. (1991). Situated learning: Legitimate peripheral participation. New York: Cambridge University Press.

Lee, H.-S., \& Songer, N.B. (2003). Making authentic science accessible to students. International Journal of Science Education, 25, 923-948.

Lee, O., \& Brophy, J. (1996). Motivational patterns observed in sixth-grade science classrooms. Journal of Research in Science Teaching, 33, 303-318. 
Linn, M.C. (1998). The impact of technology on science instruction: Historical trends and current opportunities. In: B.J. Fraser \& K.G. Tobin (Eds.). International handbook of science education (vol. 1 pp. 265-294). Dordrecht: Kluwer Academic.

Linn, M.C. (2000). Designing the knowledge integration environment. International Journal of Science Education, 22, 781-796.

Marks, H.M. (2000). Student engagement in instructional activity: Patterns in the elementary, middle, and high school years. American Educational Research Journal, 37, 153-184.

Marx, R.W., Blumenfeld, P.C., Krajcik, J., \& Soloway, E. (1997). Enacting project-based science. The Elementary School Journal, 97, 341-358.

Marx, R.W., Blumenfeld, P.C., Krajcik, J.S., Fishman, B.J., Soloway, E., \& Geier, R, et al. (2004). Inquiry-based science in the middle grades: Assessment of learning in urban systemic reform. Journal of Research in Science Teaching, 41, 1063-1080.

McGilly, K. (1994). Cognitive science and educational practice: An introduction. In: K. McGilly (Ed.), Classroom lessons: Integrating cognitive theory and classroom practice (p 317). Cambridge, MA: MIT Press.

National Research Council. (1996). National science education standards. Washington, DC: National Academy Press.

Rivet, A.E. (2006). Teachers' use of contextualizing instruction in middle school projectbased science classrooms Paper presented at the annual meeting of the American Educational Research Association, San Francisco, CA.

Rivet, A.E. (in review). Contextualizing instruction: Connecting to urban students' ideas and experiences. Journal of the Learning Sciences.

Rivet, A.E., \& Krajcik, J.S. (2004). Contextualizing instruction in project-based science: Activating students' prior knowledge and experiences to support learning. In: Y.B. Kafai, W.A. Sandoval, N. Enyedy, A.S. Nixon, \& F. Herrera (Eds.). Embracing diversity in the learning sciences: The proceedings of the Sixth International Conference of the Learning Sciences (ICLS 2004). Santa Monica, CA: Lawrence Erlbaum.

Schneider, R.M. (2001). The role of curriculum materials in reforming science education Unpublished doctoral dissertation. University of Michigan, Ann Arbor, MI.

Schneider, R.M., the Center for Highly Interactive Computing in Education (HICE). (2001). Why do I need to wear a helmet when I ride my bike? Ann Arbor, MI: University of Michigan School of Education.

Sherwood, R., Kinzer, C.K., Bransford, J.D., \& Franks, J.J. (1987). Some benefits of creating macro-contexts for science instruction: Initial findings. Journal of Research in Science Teaching, $24,417-435$.

Singer, J., Marx, R.W., Krajcik, J.S., \& Clay-Chambers, J. (2000). Constructing extended inquiry projects: Curriculum materials for science education reform. Educational Psychologist, $35,165-178$.

Songer, N.B. (1993). Learning science with a child-focused resource: A case study of kids as global scientists In Proceedings of the 15th annual meeting of the Cognitive Society. Hillsdale, NJ: Erlbaum. 